\title{
Gestão social: uma análise crítica de experiências brasileiras
}

José Antonio Gomes de Pinho

Universidade Federal da Bahia (UFBA)

Maria Elisabete Pereira dos Santos

Universidade Federal da Bahia (UFBA)

\begin{abstract}
A gestão social tem mobilizado diversos autores na academia no Brasil, estando o conceito ainda em construção, como tem sido apontado por vários autores. O objetivo deste artigo é, tendo como referência uma das construções teóricas mais recorrentes sobre gestão social, fundamentada em Fernando Guilherme Tenório, a partir da Teoria da Democracia Deliberativa de Habermas, examinar algumas experiências chamadas de gestão social, no sentido de identificar se a gestão social, como teoricamente definida, se materializa na prática na realidade brasileira. A metodologia desta investigação repousa em analisar experiências avaliadas por autores que trabalham no campo da gestão social, ou seja, são selecionadas experiências que, em tese, estariam situadas nesse campo. Os resultados, no entanto, mostram que esses próprios autores não conseguem localizar os construtos teóricos que fundamentam a gestão social, na forma como tem sido desenvolvida ou implementada. $\mathrm{O}$ artigo aponta ainda que a gestão social, na forma definida, supõe uma sociedade mais madura do ponto de vista da construção democrática, o que não encontra respaldo no processo histórico brasileiro em curso. Para tanto, de forma crítica, o artigo incorpora a visão de autores que se debruçam sobre a construção da democracia no Brasil. Assim, essa gestão social se afasta não só dos seus cânones teóricos como de uma efetiva implantação na hodierna realidade brasileira.
\end{abstract}

Palavras-chave: modelo de gestão, administração social, democracia, desenvolvimento social, teoria social

[Artigo submetido em janeiro de 2014. Versão final em dezembro de 2014.] 


\section{Gestión social: un análisis crítico de experiencias brasileñas}

La gestión social ha movilizado varios autores de la academia en Brasil, siendo que el concepto está todavía en construcción, como ha sido señalado por varios autores. El propósito de este artículo es, teniendo como referencia una de las construcciones teóricas más frecuentes, sobre la gestión social basada en Fernando Guilherme Tenório y, partiendo de la Teoria de la Democracia Deliberativa de Habermas, examinar algunas experiencias que se suele llamar de Gestión Social con el fin de identificar si esta gestión social, tal como se define en la teoría, se materializa en la práctica de la realidad brasileña. La metodologia de investigación se basa en análisis de experimentos evaluados por los autores que trabajan en el campo de la gestión social, es decir, experimentos que según esta teoría se encuentran en el campo de la gestión social. Los resultados, sin embargo, muestran que estos mismos autores no logran localizar los constructos teóricos que subyacen a la gestión social, en la forma como ha sido desarrollada o implementada. El artículo también señala que la gestión social, como se suele definir, supone una sociedad más madura desde el punto de vista de la construcción democrática, lo que no es compatible con el proceso histórico brasileño en marcha. Con este fin, este artículo recoge críticamente la visión de autores que se centran en la construcción de la democracia en Brasil. Por lo tanto, esta gestión social se aparta por completo, no sólo de sus cánones teóricos, como también de una efectiva implementación en la realidad brasileña actual.

Palabras clave: modelo de gestión, administración social, democracia, desarrollo social, teoría social

\section{Social management: a review of Brazilian experiences}

Social Management has mobilized several authors in the Academy in Brazil, being the concept still under construction, as have being pointed out by many authors. Taking as starting point the well-known theoretical construction made by Fernando Guilherme Tenório based on the deliberative democracy of Habermas, the goal of this article is to examine whether some experiences of the so-called social management have been found in practical terms in the Brazilian context. The methodology adopted in this article lies on analyzing experiences taken by their authors as belonging to the field of social management. The results, however, show that these authors themselves cannot identify social management in the theoretical way they support. The article points out that social management in the hegemonic theoretical way demands a society more developed in terms of democracy than the Brazilian one is. In order to achieve this, the article considers approaches made by authors who have seen the construction of the Brazilian democracy in a critical perspective. This being so, such social management is too far from its theoretical basis as from an effective implantation in the Brazilian context.

Keywords: management model, social administration, democracy, social development, social theory 


\section{Introdução}

Gestão social (GS) tem sido um termo recorrente nas últimas décadas, mais ainda neste começo de século. A expressão é fruto de um processo de construção teórica, mas, sobretudo, é resultado de práticas governamentais e da sociedade civil que, uma vez instaladas ou estabelecidas, se mobilizaram em busca do necessário referencial teórico. Do ponto de vista prático, da ação, a noção de GS aparece hodiernamente como uma nova vestimenta para algo que se faz há algum tempo, sendo essa ação definida pela sua associação ao que o senso comum convencionou chamar de questão social. Assim, vasculhando a história recente, o termo nos remete a temas como desenvolvimento social, política social, mudança social, inclusão social (essa mais recente), ação social e tantos outros. A GS poderia ser, então, reconhecida como a forma mais recente para enquadrar o tipo de ação que, tradicionalmente, a literatura qualifica como coletiva ou social, ou seja, ações relativas a grupos ou segmentos sociais qualificados como desfavorecidos, marginalizados, excluídos.

Parece oportuno apresentar, ainda que de forma sintética, algumas definições conceituais de GS. Certamente que a forma como se define conceitualmente a GS pode implicar coisas diferentes. Inicialmente, vale dizer que os diversos autores envolvidos nesse propósito convergem para o fato de que GS é ainda um conceito em construção, enfatizando, sobretudo, o que GS não é. A princípio, a GS não é propriamente gestão privada nem pública - ao menos quando referida ao que convencionalmente se define como público e privado. Segundo algumas abordagens, a GS é composta, sobretudo, por "associações" que "não perseguem objetivos econômicos" (FrançA FILHo, 2008, p. 32). Nessa visão, as organizações de GS estão comprometidas com uma "postura ética da conduta, a valorização da transparência na gestão dos recursos e a ênfase sobre a democratização das decisões e das relações na organização" (FrançA FILHo, 2008, p. 33). Assim sendo, visam à construção de uma "nova cultura política", objetivando quebrar com "práticas de poder despótico, frutos de uma cultura clientelista e personalística" (FrAnÇA FILHO, 2008, p. 33). Percebe-se, nessa definição, a pretensão de romper com traços estruturais da sociedade brasileira, de romper com os vícios de uma sociedade "atrasada".

Outra característica da GS apontada recorrentemente é que, enquanto na gestão pública e privada ocorre a "primazia da chamada racionalidade instrumental", que torna o social, o político, o ecológico, o estético "subordinados ou reféns do econômico" (SCHOMMER; FrANÇA FILHO, 2008, p. 67), a GS, por sua vez, atua no circuito que não é público nem privado, mas público não estatal. Nesse caso, as organizações de GS "não perseguem objetivos econômicos" (SCHOMMER; FRANÇA FILHO, 2008, p. 67). 
A construção teórica de GS desenvolvida por Fernando Tenório difere, em termos dos seus pressupostos, das anteriores e tem produzido impactos interessantes, sendo a mesma ancorada em um referencial teórico já consolidado, o da democracia deliberativa de Habermas. Para Tenório, a GS deve ser entendida "como o processo gerencial dialógico em que a autoridade decisória é compartilhada entre os participantes da ação", de modo que "todos têm direito à fala, sem nenhum tipo de coação" (TENóRIO, 2008, p. 39). Identifica-se aqui um pré-requisito fundamental, qual seja, a sociedade na construção habermasiana tomada de empréstimo por Tenório deve ser "uma sociedade de pessoas ativas e democráticas "(TENórıo, 2008 , p. 42). Configura-se, assim, a construção de uma relação coletiva na qual "o poder se dilui entre os participantes", gerando uma situação em que não existem "donos do poder" (TenóRIO, 2008, p. 49). A categoria de participação assume um papel central nessa construção, no sentido de que a GS "deve ser praticada como um processo intersubjetivo, dialógico em que todos têm direito à fala", e no qual tem lugar um "cidadão deliberativo" (TENóRıO, 2008, p. 54).

Trata-se de uma construção teórica da noção de GS ambiciosa, pretensiosa, assentada no referencial da democracia deliberativa de Habermas. Colocando de forma sintética algumas das definições dos conceitos de GS por parte de alguns dos seus formuladores, neste artigo, vamos nos deter na análise de algumas experiências de GS, com o objetivo de abrir um diálogo e fazer uma crítica aos estudos ditos de GS, de modo a contribuir para o avanço do entendimento do tema, tomando como base o referencial desenvolvido por Tenório, por ser o que tem o maior número de seguidores. Parece-nos útil abrir um diálogo com as análises de experimentos empíricos, de modo a verificar a dimensão propriamente ontológica do que hodiernamente se qualifica como GS, esclarecendo como as múltiplas expressões ou conceitos se materializam na prática.

Trata-se, portanto, do ponto de vista metodológico, da análise de um conjunto de experiências descritas pela literatura, sendo a principal preocupação deste texto avançar na construção da resposta à seguinte questão: o que é gestão social? A seleção dos referidos textos se justifica por se constituírem em exemplos de abordagem e objetos sobre os quais os teóricos da GS têm se debruçado e por se referirem a realidades econômicas, sociais, políticas e regionais diferenciadas. Discutiremos a tese de que as experiências de gestão analisadas - enfeixadas sob o genérico conceito de GS - estão, como as próprias análises e elementos empíricos apresentados revelam, distantes de concretizar a promessa de construção de uma democracia deliberativa, fundamento da GS, ainda que territorialmente circunscrita. Os desafios apresentados pelas experiências descritas colocam em debate desafios estruturais da construção democrática no Brasil e na América Latina, o que nos reporta à necessidade de superação de assimetrias de natureza econômica, social, 
como também política - particularmente as práticas patrimonialistas, que moldam a relação entre Estado e sociedade, como também a vida coletiva.

\section{A construção teórico-prática do conceito de gestão social}

A análise de experiências empíricas qualificadas como GS situa-nos em um vasto campo teórico. Em muitas das tentativas de construção do referido, observa-se um certo deslocamento da noção de público para a de coletivo, sendo essa última relacionada a valores e a possibilidades de interação mais amplos. Entretanto, o que exatamente está sendo qualificado como GS, quais conceitos emanam da sua prática e quem são os seus sujeitos, individuais e coletivos? lizuka e Junqueira (2012), ao realizarem estudo bibliométrico na área de GS, questionam "a sua existência enquanto teoria, seja pela pertinência do próprio conceito (a gestão seria inevitavelmente social, dado que lida com pessoas), seja pela possibilidade de se constituir como área autônoma de conhecimento". Os autores constatam que existe "um debate em construção", havendo também uma busca "por um caminho teórico mais sólido e robusto" (IIZUKA; JUNQUEIRA, 2012, p. 10).

Os referidos autores refazem, de forma resumida, o percurso do conceito de GS, no qual Tenório assume um papel central. Os debates iniciais em torno desse conceito, no Brasil, como registrado em vários trabalhos do referido autor, ocorrem no início da década de 1990 e contemplam, sobretudo, organizações e ações do chamado terceiro setor. Com as mudanças no papel do Estado a partir dos anos 1990, emerge um novo tipo de gestão, como afirma Tenório (2009), que substitui ou complementa a ação do Estado, particularmente no campo do planejamento, na implantação de políticas sociais e na gestão de programas sociais, conforme historiam os autores. Assim, seguindo as pegadas de Tenório, a GS passa a ser uma forma de gestão que valoriza a participação, a inclusão, tendo a solidariedade como base - a GS teria como marca o seu caráter propriamente coletivo, contraposta à gestão estratégica, que expressa um caráter individual, dado que se baseia no monólogo e no indivíduo (IIZUKA; JUNQUEIRA, 2012).

Os teóricos da gestão social, tais como Tenório (2008), Fischer (2002), Fischer e Melo (2006), França Filho (2008), parecem comungar com a noção de um processo de gestão dialógico e transparente, em que os participantes se comunicam livremente na formação de consensos (IIZUKA; JUNQUEIRA, 2012). Nesse caso particular, nem sempre é suficientemente claro quais são os projetos políticos aos quais os mencionados autores estão se reportando ao se referirem às possibilidades e potencialidades políticas, quando se reportam ao conceito de GS. No caso particular dos anos 1990, trata-se do projeto neoliberal ou das mais variadas propostas e modelos gestados ao longo do processo de redemocratização e que, 
em certa medida, se contrapunham ao projeto hegemônico em curso? Vejamos o que a prática, a empiria pode dizer sobre isso.

O estudo bibliométrico realizado por lizuka e Junqueira (2012) tomou como fonte principal e única de pesquisa os artigos apresentados no EnAPEGS (Encontro Nacional de Pesquisadores em Gestão Social), lócus por excelência da veiculação da produção de GS, iniciado em 2007, e que vem apresentando, a partir de 2010, um número crescente de artigos submetidos, totalizando 434 artigos nas seis edições desse evento. Nesse conjunto, "foram encontrados 61 artigos que tinham como temática principal a GS", sendo a GS, especificamente, mencionada no título do trabalho. Os autores justificam essa escolha argumentando que "em geral, é a partir do título que os autores definem os conteúdos mais relevantes a serem apresentados ao longo do artigo", resultando em média "16\% de artigos com a temática da GS" (IIZUKA; JUNQUEIRA, 2012, p. 7). Entre os $84 \%$ dos artigos relacionados, apareceram outros temas tais como: "economia solidária, empreendedorismo social, políticas públicas, sustentabilidade, responsabilidade social das empresas", entre outros assuntos. Os autores atribuem essa diversidade temática a "uma postura mais inclusiva desse evento científico, ao mesmo tempo em que parece apontar para um campo de conhecimento em processo inicial de construção" (IIZUKA; JUNQUEIRA, 2012, p. 8). Consideramos que essa explicação apresentada pelos autores do levantamento bibliométrico comporta outra interpretação. Causa espanto que em um encontro sobre GS que ocorre há seis anos, e com uma quantidade expressiva de artigos apresentados, apenas $16 \%$ do conjunto total sejam de artigos da temática à qual o evento se destina. Isso poderia indicar que, efetivamente, os artigos que tratam da gestão social, de forma mais estrita, são poucos. Pode também estar indicando que, por não haver precisão conceitual sobre o que se está falando, então tudo cabe, desde que margeie o tema.

O levantamento bibliométrico ainda indicou que $23 \%$ dos artigos são ensaios teóricos, o que estaria a indicar a existência de "uma área científica que está em construção" (IIZUKA; JUNQUEIRA, 2012, p. 10). Quanto aos autores envolvidos nesse esforço teórico e empírico, os mais citados (com pelo menos 10 citações), tomando apenas os autores nacionais que tratam objetivamente dessa temática, estão identificados no Quadro 1.

\section{Quadro 1: Referências mais citadas}

\begin{tabular}{l|l}
\hline Autor & $\mathbf{N}$ \\
\hline 1. TENório, Fernando Guilherme & 83 \\
\hline 2. FrançA FILHO, Genauto Carvalho de & 35 \\
\hline 3. FISCHER, Tânia & 21 \\
\hline 4. DOWBOR, Ladislau & 13 \\
\hline 5. BOULLOSA, Rosana F. & 12 \\
\hline
\end{tabular}




\begin{tabular}{l|c}
\hline Autor & $\mathbf{N}$ \\
\hline 6. SCHOMMER, Paula Chies & 11 \\
\hline 7. PAES DE PAULA, Ana Paula & 10 \\
\hline 8. LeITÃo, Sérgio Proença & 10 \\
\hline Total & 195 \\
\hline
\end{tabular}

Fonte: luzuka e Junqueira (2012), a partir dos Anais dos ENAPEGS (2007, 2008, 2009, 2010, 2011 e 2012).

Pode-se identificar um autor, Fernando Guilherme Tenório, despontando bem à frente com um número elevado de citações, indicando ser o mesmo uma referência na área, secundado por Genauto França Filho, com um número expressivo de citações, seguido por Tânia Fischer, também com um número significativo de referências, seguidos por um pelotão de outros autores bem citados. Nesse contexto teórico nem sempre convergente quanto ao que se qualifica como GS, têm sido poucas as iniciativas voltadas à discussão e questionamento dos seus fundamentos teóricos, como também das possibilidades e limites das práticas inspiradas pelo mesmo. Em um contexto de certa "calmaria" e poucos embates teóricos, é oportuno citar o artigo de José Antonio Pinho, apresentado no III ENAPEGS, em Juazeiro e Petrolina, em 2009, que formula uma crítica à forma como a GS vem sendo teoricamente concebida e também levanta questionamentos sobre as condições necessárias à construção de uma democracia deliberativa, nas atuais circunstâncias históricas do Brasil. Essa crítica parece ter estimulado uma revisão do conceito de GS pelos seus originais formuladores, preocupados com a constituição desse campo teórico.

Pinho e Santos (2013) empreendem uma análise reforçando a crítica ao conceito de GS, mais especificamente à forma como Tenório o constrói a partir do referencial habermasiano. Para os referidos autores, a associação do conceito de GS às noções de esfera pública e emancipação traz consigo equívocos na interpretação de Habermas, o que dificulta a pretensa virada conceitual realizada por Tenório, ao tentar pensar a GS nas condições brasileiras. Ademais, os autores em tela continuam batendo na tecla da inadequação do conceito de democracia deliberativa, um dos fundamentos do conceito tenoriano de GS, às perenes condições da construção democrática no Brasil. E não basta recorrer ao argumento de que uma vez que não estão dadas as condições necessárias à construção da democracia deliberativa, trata-se de criá-las - sendo a GS um instrumento a serviço dessa causa. Nesse exato sentido, é preciso lembrar a formulação de Marcos Nobre quando afirma ser necessário pensar a nossa capacidade de refletir, de produzir uma teoria sobre o Brasil. A importação de teorias, ou a apropriação desavisada de teorias, em linhas gerais, reflete a existência de lacunas no campo teórico e mesmo ideológico do País, sendo um dos traços mais característicos do que, historicamente, alguns teóricos 
qualificam como subdesenvolvimento (sem entrar aqui no mérito da pertinência do debate suscitado por esse conceito e pelas noções de centro e periferia). Como afirma Nobre, "mimetizar a teoria em voga nos países centrais sem a substância social e cultural que lhe dá sentido impede uma reflexão de fundo, abrangente, sobre a própria realidade social brasileira". Esse tipo de postura "bloqueia não só a teoria, mas a própria formação do País, limitando de saída sua autocompreensão e suas possibilidades práticas" (NOBRE, apud Melo, 2013, p. 15).

Este artigo, como dito anteriormente, inspirado nesse debate teórico, voltase para a análise de experiências de GS, de modo a verificar as possibilidades de concretude e seu alcance na realidade brasileira. Não se pretende com essa iniciativa dar conta de toda a diversidade teórica e prática contida nesse "campo" de saber (como diriam alguns formuladores do conceito de GS inspirados em Bourdier). Pretende-se apenas, de forma cautelosa, contribuir com o debate em torno de algumas abordagens e algumas das práticas inspiradas por alguns dos seus autores.

\section{Dialogando com ditas experiências de GS}

Vamos tomar como base de reflexão para este exame cinco artigos da publicação Gestão social - aspectos teóricos e aplicações, organizada por Airton Cançado, Fernando Tenório e Jeová Torres Silva Jr, membros do core da GS no Brasil. A publicação conta com contribuições de relevantes pesquisadores envolvidos na discussão da GS, voltadas mais especificamente para experiências práticas, exatamente com o objetivo de verificar se propósitos teóricos construídos no campo de debate teórico-conceitual são encontrados na prática. Temos à disposição um elenco variado de experiências, tanto em termos de áreas de atuação quanto de áreas geográficas.

Comecemos com o texto "Avaliação de processos decisórios participativos no polo comercial Saara situado na cidade do Rio de Janeiro - uma fórmula de sucesso com problema em seu princípio ativo, a participação", que visa "demonstrar a dinâmica de participação e de deliberação dos atores envolvidos no polo comercial Saara" (VILLELA; COSTA, 2012, p. 58), no Rio de Janeiro, que trata do funcionamento de uma associação de comerciantes com meio século de existência. O objetivo da investigação é verificar como ocorre "a GS dos atores envolvidos no polo comercial Saara", mais especificamente "como se dão os processos decisórios participativos e deliberativos" (VILLELA; COSTA, 2012, p. 58). Desse modo, o texto parte do pressuposto da existência do que ele qualifica como GS e se propõe a investigar como a mesma ocorre.

Não apresentaremos aqui o processo histórico de constituição desse polo, devendo os interessados consultar o referido artigo. Importante destacar, no entanto, que a GS é, aqui, entendida a partir do referencial habermasiano da democracia 
deliberativa, que considera a "participação de todos os atores sociais envolvidos na questão em pauta de forma direta ou indireta". Os atores são vistos como "potenciais protagonistas de seus interesses buscando o entendimento" (VILLELA; COSTA, 2012, p. 66). Com fundamento em formulações de Tenório, afirma-se que "os atores não irão impor suas propostas, e, sim, buscarão validá-las em acordo oriundo do diálogo entre os participantes" (VILLELA; COSTA, 2012, p. 67). Assim sendo, "as ações serão fruto de relações dialógicas e não de relações monológicas. O diálogo constrói o consenso entre os atores e visa ao bem comum de todos" (VILLELA; COSTA, 2012, p. 67). A pesquisa empírica abarca um conjunto de 30 empresários e 11 trabalhadores do polo, aos quais foram aplicados questionários diferenciados. Os autores relatam a grande dificuldade em aplicar os questionários para o grupo dos trabalhadores, "seja por questionamentos velados por parte de gerentes e proprietários ou falta de interesse desses mesmos trabalhadores em responder aos formulários" (VILLELA; COSTA, 2012, p. 70).

A análise do material empírico indicou "a não existência de mecanismos participativos característicos de uma gestão social" (VILLELA; CoSTA, 2012, p. 77), ou seja, a pesquisa de campo realizada mostrou "uma fraca participação dos comerciantes junto à associação", tendo como base, ao que parece, o fato de o presidente da associação ter sido reeleito há 15 mandatos sucessivos, ancorado no "grande sucesso comercial do polo" (VILLELA; COSTA, 2012, p. 79). Assim, os autores concluem que "a centralização decisória compromete sobremaneira uma GS em sua dimensão participativa e dialógica, na perspectiva de Tenório et al. (2008), tendo inevitáveis reflexos em sua governança e em seu desenvolvimento local" (VILleLA; COSTA, 2012, p. 81). Concluem também que "se tornaram incipientes os processos participativos no polo em relação ao que poderia ser" (VILLELA; CoSTA, 2012, p. 82). Sendo assim, não foram encontrados nessa experiência os pilares básicos do que os autores qualificam como GS; aliás, o próprio título do artigo já explicita que o "princípio ativo, a participação" se constituía em "problema" na experiência analisada. Desse modo, a análise do processo, do como, explicita o vazio das pretensões do próprio texto, uma vez que a questão central colocada carece de sentido, ou seja, a pergunta sobre "como se dá a GS dos atores envolvidos no polo comercial Saara" é um anacoluto lógico (a pergunta, do ponto de vista lógico, não tem consequência) - o texto, na verdade, pergunta-se sobre como ocorre algo que, de resto, não existe.

Um segundo artigo dessa mesma publicação é de autoria de Jeová Torres Silva Junior e Rebeca da Rocha Grangeiro (2012), intitulado "Gestão social, finanças solidárias e desenvolvimento territorial: os impactos dos 10 anos de atuação do Banco Palmas". Nesse artigo, o conceito de GS está no título, mas o artigo, surpreendentemente, não trata de GS, nem de uma perspectiva teórico-conceitual, nem aplicada (os conceitos-chave do texto são finanças solidárias e desenvolvimento 
territorial). A GS aqui parece ser um tipo de chave mestra que abre todas as portas ou um coringa - trata-se, entretanto, de apenas um título. O uso recorrente da expressão GS parece querer indicar um posicionamento ideológico, social por parte dos autores, de modo a mostrar que o debate travado ou a experiência analisada implica engajamento, que existem boas intenções, que existe compromisso social. Apenas nos estertores do artigo aparece a expressão GS, quando o mesmo afirma que a criação da Rede Brasileira de Bancos Comunitários foi "um largo passo para a solidificação dos processos de GS desses bancos comunitários" (SILVA JUNIOR; GRANGEIRo, 2012, p. 115). Assim, a GS aparece como um pressuposto, como um taken for granted que se pratica uma GS, mesmo que em todo o texto o referido conceito apareça apenas de forma periférica.

Um terceiro artigo, intitulado "Gestão social aplicada às políticas públicas de desenvolvimento territorial rural no Brasil: o caso do Território da Cidadania Norte do Rio de Janeiro", de autoria de Felipe B. Zani, Thais S. Kronenberger e Anderson F. Dias (2012), faz um levantamento teórico padrão do que entende por GS: cidadania, democracia deliberativa, dialógica, pluralismo. O texto aborda a "perspectiva territorial como gestão social" e a gestão da política de desenvolvimento territorial rural é concebida a partir da dimensão propriamente local, de uma abordagem bottom-up, que requer e demanda a participação (ZANI; KRONENBERGER; DIAS, 2012, p.120). O texto estuda a experiência de implementação do Programa Territórios da Cidadania (PTC), na região Norte do Estado do Rio. Inspirados em uma das dimensões do conceito de GS, formulado por Tenório (processo dialógico de compartilhamento de autoridade), os autores afirmam que as ações a serem desenvolvidas no referido território deveriam ser "viabilizadas por uma relação dialógica entre representantes do Estado, da sociedade civil e do mercado" (ZANI; KRONENBERGER; DiAS, 2012, p. 120). No entanto, ao fazer a análise empírica, o texto mostra como a própria construção do território de identidade se afasta de uma postura democrática, uma vez que é imposta de cima para baixo, pelo Governo Federal, pelos ministérios envolvidos, sobre a comunidade. Assim, registram os autores, "ao contrário das políticas europeias e norte-americanas para o desenvolvimento territorial, nas quais a formação dos territórios parte da mobilização dos próprios grupos locais, no caso brasileiro trata-se de uma prerrogativa essencialmente centralizada pelo governo" (ZANI; KRONENBERGER; DIAS, 2012, p. 142). A formação dos territórios mostra-se aqui "uma prerrogativa governamental, em vez de provir da iniciativa local" (ZANI; Kronenberger; Dias, 2012, p. 145). Podemos dizer que, desde o nascedouro, tal experimento já se contradiz, pois resulta de uma decisão centralizada, constituindose em um exemplo da nossa tradição autoritária, ainda que, supostamente, in dubio pro reo, voltada à prática de uma gestão democrática (conceito que não chega a ser discutido ao longo do texto). 
Ao tratar da GS, o texto ainda recorre à definição do Ministério do Desenvolvimento Agrário (MDA), segundo o qual a "gestão social é a forma de gerir assuntos públicos, em particular as políticas e iniciativas voltadas para a promoção do desenvolvimento das áreas rurais" (ZANI; KRONENBERGER; DIAS, 2012, p. 133), uma construção bem menos ambiciosa e mais pragmática do que a inspirada por Tenório. A análise realizada se dirige ao conflito entre representantes empresariais e representantes da agricultura familiar, e os autores concluem que "o modelo de GS praticado no norte fluminense não conseguiu promover a concertação das forças sociais dinâmicas presentes no território", o que nos leva à compreensão de que estamos, em verdade, diante de um contra exemplo de GS, que reproduz a tradição centralizadora, historicamente praticada no País, como também explicita as assimetrias e conflitos de classes presentes no campo brasileiro. É importante registrar que os dados empíricos apresentados no texto (em particular a natureza dos conflitos entre os agricultores familiares e os empresários) são suficientes para se concluir o quão difícil deve ser a operacionalização do conceito de GS sugerido por Tenório e incorporado pelos referidos autores, ou seja, a construção de esferas públicas e projetos de desenvolvimento que envolvam o diálogo democrático entre Estado, sociedade civil e mercado. A dimensão política do que é qualificado como GS aparece nas entrelinhas do texto, quando o mesmo afirma que "a situação de desigualdade comum às regiões rurais corrói o tecido social enquanto vivência solidária, compartilhada, identitária entre seus atores" (ZANI; KRONENBERGER; DiAS, 2012, p. 148). Em síntese, o texto contém, do ponto de vista argumentativo, a sua própria antítese.

Como alento, o trabalho conclui que a experiência "foi responsável pelo empoderamento das organizações da sociedade civil, que, além de acompanharem os investimentos públicos realizados na região, tiveram forças inclusive para resistir à instituição do Programa Territórios da Cidadania", o que é um resultado surpreende, pois a população, a sociedade civil se colocou contra um programa que, inspirado no conceito de GS, em tese, a estaria beneficiando (ZANI; KRONENBERGER; DIAS, 2012, p. 151).

Um quarto artigo analisado é o "Gestão social no contexto do Programa Territórios de Cidadania: a experiência de alguns municípios do noroeste gaúcho" de Sérgio Luís Allebrandt, José Roberto de Oliveira e Cristiele Tomm Deckert (2012). O texto pretende verificar quais avanços a gestão social tem produzido em termos de cidadania na realidade estudada, e define o referido conceito a partir de autores como Singer, Dowobor, Fischer, França Filho, bem como o próprio Allebrandt e, sobretudo, Tenório, esclarecendo que "o tema gestão social tem sido evocado nos últimos anos para acentuar a importância das questões sociais para os sistemas-governos, sobretudo na instituição de políticas públicas, assim como dos sistemas-empresa no gerenciamento dos seus negócios" (AllebrandT; OliveiRA; DECKERT, 2012, pág. 158). O texto se situa, à luz da interpretação de Tenório da teoria habermasiana, no contraponto entre a 
ação estratégica e a ação comunicativa e define a GS como a ação comandada pela razão comunicativa, pelo agir comunicativo que "enfatiza a ação gerencial dialógica, participativa" e tem como protagonistas os sujeitos sociais. Trata-se de uma gestão "baseada no entendimento mútuo entre os atores/sujeitos, na harmonização interna dos planos de ação pelos atores" e que "exige a presença do discurso argumentativo", que deve passar pelo crivo da veracidade, correção normativa e autenticidade, sendo a cidadania deliberativa a base de tal construção (ALLEBRANDT; OLIVEIRA; DECKERT, 2012, p. 161). Os autores são enfáticos ao afirmar que a GS requer "a substituição do enfoque estadocêntrico e/ou mercadocêntrico por um enfoque sociocêntrico, no qual a sociedade civil aparece como sujeito do processo" (ALLEBRANDT; OLIVEIRA; DECKERT, 2012, p. 158-162).

Essa mudança de posicionamento demanda "a construção de um novo triângulo social, em que a sociedade civil passa a ocupar uma posição de destaque, e a cidadania emerge como protagonista no processo dessas novas relações" (AllebrandT; OliveirA; DeCKERT, 2012, p. 162). Assim, “[a] gestão pública e a gestão do desenvolvimento constituem-se em locus privilegiado, em espaço público para a prática da gestão social" (ALLEBRANDT; OLIVEIRA; DECKERT, 2012, p. 162). Vale notar que, em uma frase pequena, a palavra gestão aparece três vezes, qualificada como pública, do desenvolvimento e social. Queremos entender que os autores pensam que GS é uma forma de qualificar a gestão, seja ela pública ou do desenvolvimento. Por fim, os autores encerram a formatação do quadro teórico afirmando que "a GS do desenvolvimento local/regional" não pode ser pensada "sem articular os conceitos de participação, cidadania, democracia e descentralização [...]" (Allebrandt; Oliveira; DeCKert, 2012, p. 162).

$\mathrm{O}$ arcabouço desse artigo, a exemplo do anterior, reporta-se também à definição de GS do MDA, que aponta dois critérios essenciais para que o processo de GS possa ocorrer: "ter um ambiente marcado pela descentralização política e administrativa e criar maneiras de conduzir ao empoderamento da sociedade" (AllebrandT; OLIVEIRA; DECKERT, 2012, p. 165). Mais ambiciosamente, o MDA estabelece que todos os interessados nas ações pactuadas estejam presentes em todos os momentos do processo. Assim, a partir dos documentos do MDA, os autores, cristalinamente, reafirmam a posição de que "a GS deve envolver os atores num processo democrático e transparente, que rege as ações trabalhadas no interior dos territórios; afinal, é dentro dos processos participativos que os indivíduos adquirem novos conhecimentos sobre sua realidade e desenvolvem capacidades de transformá-las" (ALLEBRANDT; OLIVEIRA; DECKERT, 2012, p. 165).

O MDA concebe um ciclo de GS que parte da "sensibilização e mobilização dos atores locais, avança pela construção da visão compartilhada de futuro e do diagnóstico participativo da situação nela envolvida, passa pelo planejamento" 
(AllebrandT; OliVeIRA; DeCKERT, 2012, p. 166), chegando à proposição de políticas e projetos, alcançando, ao final, o monitoramento dos mesmos. Um requerimento fundamental reside no controle social visto pelo MDA como a "participação da sociedade no acompanhamento e na verificação das ações da gestão pública na execução das políticas, avaliando os objetivos, os processos e os resultados" (AllebrandT; Oliveira; DeCKert, 2012, p. 167).

Incorporado o referencial teórico, ao determo-nos na análise empreendida pelos autores sobre o estudo de caso, o Território de Cidadania do Noroeste Gaúcho (TC-Norc) revela-se outra realidade. Em primeiro lugar, não existe uma integração de ações no âmbito federal com os demais níveis de governo; não só os territórios como os municípios "não possuem participação na definição das políticas públicas que impactam as regiões" (ALLEBRANDT; OlIVEIRA; DECKERT, 2012, p. 179). Isso está presente nas manifestações de gestores, agentes públicos, lideranças sindicais e de movimentos sociais, empresários e representantes da sociedade civil, junto à coordenação do programa, sendo que uma grande parte dos interessados "mostrou desconhecimento" do programa (AllebrandT; OliveiRA; DeCKERT, 2012, p. 180).

Em segundo lugar, outra faceta identificada é a falta de participação, sendo que um secretário municipal de administração mostrava-se "desgostoso com a pouca participação da sociedade" (AlLEBRANDT; OliveIRA; DeCKERT, 2012, p. 181), apesar dos convites feitos para as reuniões de audiências públicas. Um secretário de planejamento atesta que os planos e orçamentos municipais "são feitos basicamente no papel [...]. O povo não é acostumado a se reunir para discutir o orçamento e a ação pública. A Secretaria da Fazenda é quem constitui o plano" (AllebrandT; OLIVEIRA; DECKERT, 2012, p. 181). Um prefeito da região aponta, ainda, que "o povo não vem para a discussão, e quando vem, fala da necessidade individual [...] falta a visão da coletividade e do bem comum" (ALLEBRANDT; OliveIRA; DECKERT, 2012, p. 182).

Os autores entendem que essa situação é bem representativa de um todo, pois, apesar de toda a experiência amealhada no Rio Grande do Sul com orçamento participativo e consultas populares, "a dinâmica de elaboração dos orçamentos municipais ainda é altamente centralizada e de caráter técnico". Mais ainda, os prefeitos convocam as audiências públicas por "obrigação legal", acontecendo na prática que "o processo é meramente burocrático na maioria das vezes, sem um real incentivo à mobilização da comunidade e dos cidadãos" (ALLEBRANDT; OLIVEIRA; DECKERT, 2012, p. 182), resistindo "a abrir o orçamento municipal à deliberação da população, pois isso significa dividir o poder com a sociedade, o que para muitos, não está na ordem do dia" (Allebrandt; OliveirA; DeCKERT, 2012, p. 182). Percebese, assim, o esboroamento de todos os requisitos pontuados por uma GS tanto postulada pelo MDA, como pelos teóricos rigorosos da gestão social. 
Mesmo os mais otimistas, como um presidente de sindicato dos trabalhadores rurais de um dos municípios, que enxerga a participação do sindicato de "forma democrática e transparente", logo em seguida se diz "desmotivado" a participar das demais reuniões, considerando que "quem toma as decisões são "pessoas apadrinhadas'" (ALLEBRANDT; OLIVEIRA; DECKERT, 2012, p. 183). Um presidente de um dos sindicatos de trabalhadores rurais também se manifesta de forma pessimista em relação ao programa, pois, no seu entender, "reúnem as pessoas para votar no que já estava definido e não propriamente para decidir" (ALLEBRANDT; OLIVEIRA; DECKERT, 2012, p. 185).

Os coordenadores do programa no TC-Norc atestam que "não tem participação na definição, nem na execução das ações previstas nesses recursos". Apesar da votação nas consultas populares, as demais relações se expressam por meio de "modelos de gestão estratégica, em que a ação social é utilitarista", emergindo "a predominância do comportamento tecnoburocrático" (AllebrandT; OliveirA; DECKERT, 2012, p.189). Assim, observa-se "uma razoável distância entre a concepção e o planejamento de uma política pública voltada ao desenvolvimento territorial e à consequente redução das desigualdades sociais, e a efetiva prática que pressupõe a gestão social [...]" (Allebrandt; Oliveira; DeCKert, 2012, p.190). No entender dos autores da análise, "as causas desse distanciamento" podem ser atribuídas ao "desinteresse ativo da população, à falta de informações sobre os projetos e de como participar dos mesmos, a uma cultura que ainda preserva o individualismo em detrimento do coletivo e do bem comum, às estruturas tecnoburocráticas que coordenam e/ou executam as políticas públicas" (AlLEBRANDT; OliVeIRA; DeCKERT, 2012, p.190). Verifica-se, assim, que a GS, apesar de todas as boas intenções preconizadas pelos seus teóricos, esbarra em obstáculos estruturais do processo histórico brasileiro.

Um último texto fecha esse conjunto de artigos que se voltam para experiências práticas de GS, de autoria de Sérgio Luís Allebrandt, Carlos José Marin Filho e Larissa Lucchese Ceratti, intitulado "Políticas públicas sociais e de desenvolvimento local no noroeste gaúcho". O estudo realizado em seis municípios do noroeste gaúcho é entendido como passível de gerar uma contribuição para "o avanço da teoria social, da administração pública e da gestão social" (AlLEBRANDT; MARIN FILHO; CERATTI, 2012, p. 195). O referencial teórico é fundamentalmente assentado no desenvolvimento local, baseando-se em Tenório, revelando a necessidade de "adoção da gestão social, participativa, dialógica, em substituição à gestão tecnoburocrática, monológica, estratégica, modelo presente por excelência nos sistemas-governo (TENóRIO, 1999)" (Allebrandt; Marin Filho; Ceratti, 2012, p. 205). O estudo faz uma análise da fragilidade dos pequenos municípios, suas atribuições quanto à implementação dos programas de transferência de renda do Governo Federal e repercussões desses 
no âmbito municipal, bem como políticas engendradas pelos governos locais para geração de renda.

Chegamos ao final do trabalho e praticamente o artigo não adentra em qualquer conteúdo de GS. Porém, já nos extertores do artigo, em seus últimos parágrafos, os autores concluem que "a gestão dita social praticada nos municípios estudados corresponde à ideia de gestão pública essencialmente vinculada à busca de soluções imediatas para os problemas denominados sociais, distante da concepção matriz de incorporação da sociedade no processo de planejamento e execução de políticas públicas" (Allebrandt; MARIn Filho; CerattI, 2012, p. 219). Dessa afirmação, podemos extrair duas posições. Por um lado, embora a expressão ou conceito de GS não tenha aparecido ao longo do trabalho, surge abruptamente ao seu final, o que parece indicar que por GS pode-se entender tudo ou qualquer coisa relativa ao social de uma maneira geral; o conceito estaria subentendido. Por outro lado, os próprios autores se referem à GS como "dita", o que ainda lança mais brumas sobre sua existência. Pelo que os autores dizem na sequência, fazemos o esforço de entender que a gestão, que se está praticando, foge aos cânones do que seria a GS pensada pelos autores e aceita nessa corrente.

Em síntese, pode-se constatar que dos cinco artigos analisados, todos se referem à GS, sendo que três deles estampam a expressão nos seus títulos. Porém, nenhum deles afere positivamente a presença da GS na prática. Parece que estamos, aqui, diante de um paradoxo; os próprios autores defensores e/ou entusiastas da GS não a conseguem enxergar e perceber nas experiências práticas. Seria, assim, a GS apenas uma pretensão teórica, uma utopia? Vamos ver, na seção seguinte, aspectos estruturais do processo histórico brasileiro que, parece, impedem ou dificultam a emergência da GS, e que têm que, obrigatoriamente, ser considerados de modo a envolver a realidade concreta e examinar possibilidades de constituição da GS.

\section{Discutindo os limites e as possibilidades da GS no Brasil}

A explicação, ou a busca de explicação, da assimetria entre a teoria da GS, particularmente no que diz respeito às questões relativas à participação, e a sua prática efetiva pode ser encontrada em trabalhos como o de Schwartzman (2007), que identifica a sociedade brasileira contemporânea como uma sociedade neopatrimonialista, não devendo ser qualificada nem como moderna, nem tipicamente tradicional, mas combinando aspectos dessas duas distintas tradições. Nesse contexto, um dos grandes desafios da sociedade brasileira ainda seria a construção de uma cultura política democrática, no sentido clássico, o que implica ainda democratizar o Estado e efetivamente constituir uma sociedade civil. A despeito de todos os avanços nas últimas décadas (e já deixando expressa a consciência das 
manifestações de junho de 2013, mas, ainda, sem correr o risco de afirmações mais peremptórias), trata-se, ainda, de realizar, no âmbito da sociedade e particularmente do Estado, "a transição de uma estrutura pesada, ineficiente e embebida por um sistema de valores ultrapassado e conservador para uma estrutura ágil, moderna", capaz de superar os persistentes atrasos e subdesenvolvimento (SCHWARTZMAN, 2007, p. 37). Ainda ancorado nesse autor, "a temática do autoritarismo brasileiro não é um simples fenômeno passageiro, mas tem raízes profundas e implicações que não se desfazem por simples arranjos institucionais". Isso não quer dizer que "o Brasil padeça de um estigma autoritário congênito para o qual não existe salvação" (SCHWARTZMAN, 2007, p. 10); não se trata também de um determinismo histórico, mas, sim, de que, apesar das transformações, a tradição autoritária, pela sua resistência, ainda marca de forma indelével a cultura política brasileira nos dias de hoje.

Por outro lado, como em alguns dos casos anteriormente analisados, não há como negar a constituição, ainda que a passos lentos, do que, genericamente, se qualifica como sociedade civil; não se verificando, no entanto, a existência de uma sociedade civil mais madura, nem mesmo a sua ascendência sobre o Estado. A questão fundamental, em estados patrimoniais, não é a manutenção do "povo em situação dependente e alienada, mas, principalmente, o fato de que todas as formas de organização social que eles geram tendem a ser dependentes do poder público e orientadas para a obtenção de seus favores" (SCHWARTZMAN, 2007, p.27).

Uma análise mais estrutural do Brasil sugere que não se pode deixar de considerar as dificuldades "de desenvolvimento da democracia numa sociedade marcada por três séculos de colonização e quase quatro de escravidão" (LAMOUNIER, 2009, p. 58), aspectos estruturais que transbordam para o presente, quer de forma aberta ou velada. Assim, é fundamental levar em conta que "no Brasil, os mecanismos parlamentares e eleitorais" que fundam o Estado representativo "não se implantaram a expensas do patrimonialismo, mas enlaçados a ele. Não houve choque e, sim, enlace e complementaridade entre os dois subsistemas" (LAMOUNIER, 2009, p. 58). Isso quer dizer que a modernização da sociedade brasileira se fez de mãos dadas ao patrimonialismo, e que é preciso que se construa no Brasil, ou na America Latina, as condições políticas para a constituição de uma democracia robusta, moderna e consistente. Percebe-se, sim, a existência de "um certo autoritarismo profundamente enraizado na cultura política do País", o que representa "um obstáculo importante ao funcionamento apropriado da democracia representativa" (LAMOUNIER, 2009, p. 60).

O apreciável conjunto de mudanças ocorridas na sociedade brasileira nas últimas décadas "forçou a abertura de espaços para a vocalização dos novos interesses" e junto com "a irrefreável universalização dos direitos sociais", que batem à porta do Estado (NogueIRA, 1998, p. 217). Nesse processo histórico, foi-se construindo 
uma "vigorosa, porém confusa e dramática sociedade de massas", que convive ao lado de "enclaves de miséria e subdesenvolvimento" (NogueIRA, 1998, p. 218). Daí resulta "uma história marcada pela preeminência do Estado e pela ausência de rupturas radicais" (NogUEIRA, 1998, p. 218). Pensando no que cabe ao Estado, esse "sobrecarregou-se de atribuições [...]. Tornou-se racional-legal, sem deixar de ser patrimonialista" (NogueIRA, 1998, p. 221).

Ao tomarmos as últimas décadas, percebe-se a natureza conservadora das nossas mudanças. Mesmo movimentos com intensa mobilização, como o das Diretas já, a mudança se fez "pelo alto", foi "iniciada e controlada pelo alto" (BETHEL, 2002, p. 35), com o elemento popular sendo desconsiderado nas decisões finais; sendo que a transição do governo militar ao civil ocorreu segundo uma "transição pactuada, uma transição sem rupturas" (BETHEL, 2002, p. 36). Dessa forma, mantendo um "alto grau de continuidade institucional do regime burocrático-autoritário brasileiro", o velho estilo oligárquico baseado no clientelismo e no prebendalismo, "predominante no Brasil até o Golpe de 1964", tem sua continuidade mantida (O'DONNELL, 1988, p. 43).

Ao tratar do período mais recente, pós-Constituição de 1988 , na situação brasileira, ainda que se registrem incontestes avanços na reconstrução democrática, não existem razões para excessos de otimismo, pois "os partidos políticos perderam substância, o clientelismo se ampliou, o sindicalismo e os movimentos sociais foram cooptados e boa parte das elites patrimonialistas se mantiveram no seu poder". Assim, "a política antiga" tem demonstrado ter uma enorme capacidade de "sobrevivência e metamorfose" (SCHWARTZMAN, 2007, p.12). Essa situação atinge dramaticidade quando se considera que o eleitorado, com baixo grau de informação e liberdade de escolha reduzida, fica "vulnerável a apelos populistas, paternalistas, clientelistas" (CARVALHO, 2009, p.1). A formação de maiorias parlamentares, um requisito básico da democracia, constrói-se a partir de uma negociação de "favores e benesses" (CARVAlHo, 2009). Quanto ao Judiciário, esse é "lento e ineficiente, tornando a lei um instrumento desigual de proteção e punição" (CARVALHO, 2009, p. 1). E, mais recentemente, a situação configurou-se a partir de "um presidente popular, um Executivo hegemônico, um Congresso desmoralizado, partidos que abandonaram programas em troca de um pragmatismo radical voltado para cálculos eleitorais" (CARVALHO, 2009, pág.1). Em vez de se objetivar a construção de um governo marcado pela eficiência e transparência, foram mantidos os velhos parâmetros do "iberismo estatocêntrico e patrimonialista" (CARVALHO, 2009, p.1).

O que caracteriza nossa formação social é uma "cultura pouco propensa à confrontação ou à crítica aberta, uma vez que a pessoa nunca sabe quando poderá 'precisar' da outra num sistema cuja base de funcionamento é o favor e a boa vontade" (SORJ, 2001, p. 31, grifo nosso). Vale comentar que o "contato pessoal", 
o "favor" e a "boa vontade" estão fora de um cardápio básico para constituir uma democracia moderna, muito menos uma democracia deliberativa. Assim, existe uma "vocação do capitalismo brasileiro para adotar soluções autoritárias e repressivas como base para a obtenção do consentimento e do controle social, vocação que Gramsci chamaria de propensa muito mais para a coerção do que para o consenso" (NogUEIRA, 1998, p. 219). Visto de outra maneira, ao predominar a coerção sobre o consenso, prevalecem as decisões autocráticas e não aquelas negociadas em que a participação política assume um papel-chave.

Desse modo, estamos longe de uma democracia substantiva, moderna, menos ainda de uma deliberativa, estando a sociedade brasileira diante do desafio "republicano" de "tornar público o Estado" (SoRJ, 2001, p.76), o que demanda "desfazer as relações patrimonialistas, parasitas e corruptoras entre Estado e empresários", combinando-se com a exigência de "maior transparência e autonomia", o que requer um sistema político definido "dentro de normas que limitem a apropriação patrimonialista de recursos públicos" (SORJ, 2001, p.76). O patrimonialismo ainda exibe uma musculatura significativa como referencial teórico e prático na definição da vida política no Brasil - nada mais antirrepublicano e anticidadania deliberativa do que o patrimonialismo. É nesse contexto que a associação entre GS e democracia deve ser problematizada de forma mais profunda. Não basta, no plano da teoria, afirmar as vantagens advindas da associação de um genérico conceito de democracia a noções como deliberação, participação, entre outras, sem problematizar, de fato, no cotidiano da vida política, os significados econômico, social e político do referido conceito. Em outras palavras, não adianta fazer uma construção teórica de alto grau de desenvolvimento democrático sem refletir sobre as dificuldades estruturais resultantes da nossa formação social. Parece ficar, assim, muito mais como um estado desejável do que efetivamente real.

Essa análise do processo democrático exala no Brasil, sem sombra de dúvida, uma posição que talvez possa ser vista como pessimista. Afinal, quais as possibilidades da construção democrática no contexto brasileiro? Falar sobre democracia no Brasil é, ao mesmo tempo, temeroso, arriscado como também algo que remete à esperança, à utopia. Em termos históricos, vale lembrar que o atual período (de 1985 até o presente) é a mais longa quadra democrática de nossa história, mas não deixando de lembrar que o presidente eleito na referida data o foi de forma indireta. Assim, temos que reconhecer que nossa tradição em democracia é, de fato, incipiente. Ao estudar o processo de transição de regimes autoritários para a democracia, tanto na Europa (Portugal, Espanha e Grécia), como em vários países da América Latina nos anos 1980, O’Donnell (1988) mostra a existência de duas fases. A primeira vai do fim do governo autoritário à constituição do governo democrático, enquanto a segunda reporta-nos ao 
processo de consolidação do regime democrático. Essa última fase, diz o autor, é mais longa e mais difícil. Entendemos que o Brasil encontra-se exatamente nessa fase. Ao que tudo indica, estamos na fase da construção, consolidação e aperfeiçoamento das instituições democráticas, bem como da criação de algumas dessas. Por outro lado, ainda que as instituições tenham conseguido incorporar processos e procedimentos democráticos, ainda não existe, na maioria delas, confiança por parte da população, sendo normalmente reprovadas, a exemplo da Justiça, tida como lenta. Essa situação, no entanto, tem um caráter estrutural, pois, como afirma José de Souza Martins, o Brasil parece efetivamente ter uma História Lenta (MARTINS, 2011). Assim, temos que entender a democracia no Brasil como um processo em construção.

Certamente, estamos longe dos riscos, apontados pela máxima de Tácito, de viver uma situação caracterizada como Rara temporum felicitas ubi sentire quae velis et quae sentias dicere licet, mas ainda longe de uma democracia plena. 0 próprio O’Donnell (1991), ao estudar a situação política nos países da América Latina a partir da transição para democracia, sentiu a insuficiência dos modelos clássicos da democracia representativa. O autor constata a existência de experiências democráticas nos países do subcontinente, mas reafirma a necessidade de olhar de forma mais cuidadosa e detida para tais experiências. Tal inquietação levou o autor a criar o conceito de democracia delegativa para explicar os países latinoamericanos. Nesse arranjo, de forma resumida, os cidadãos elegem os ocupantes dos cargos públicos e delegam poder a eles, afastando-se da vida política até as próximas eleições. Assim, não é possivel negar que estamos em uma democracia, mas ainda nos falta muito para a construção de uma democracia mais substantiva. Desse modo, não estão devidamente consolidados os requisitos fundamentais da participação democrática e representativa, fragilmente praticada por nós, menos ainda de uma democracia deliberativa, de uma cidadania deliberativa.

\section{Conclusões}

Esse quadro nos leva a concluir que, apesar de impulsos modernizadores na sociedade e no Estado brasileiros, os componentes mais tradicionais e conservadores da formação social brasileira mostram uma forte resiliência, uma capacidade enorme de adaptação a novas situações, sem perder suas características originais de uma sociedade patrimonialista. O Brasil funciona em torno de parâmetros muito distantes de uma democracia deliberativa, de uma democracia com instituições sólidas e consolidadas. A democracia no Brasil, sendo otimista, está "em obras", está sendo ainda construída. Torna-se difícil, assim, identificar aqui processos e procedimentos democráticos mais substantivos, que se assemelhem a experiências 
e características de países mais maduros - o que torna ainda mais difícil localizar o desenho ou rabisco do que a literatura qualifica como democracia deliberativa, conforme os argumentos expostos pelos textos analisados, fundamentados, em geral, nas formulações de Tenório. Vale relembrar que os estudos tomados para reflexão neste artigo são experiências analisadas por defensores da GS, ou seja, por pesquisadores que acreditam e defendem a GS, bem como se servem de armaduras teóricas da GS. Em outras palavras, não estamos recorrendo, aqui, a visões de pesquisadores críticos da GS.

Isso posto, entendemos que a construção teórica da GS acaba tendo um caráter prescritivo, um dever ser, com forte carga utópica, um desejo do que deve ser ou deveria ser a sociedade brasileira (o que é, por si só, muito legítimo). Cabe ponderar ainda que as experiências identificadas, longe de transpirar características deliberativas, referem-se a programas e projetos circunscritos na esfera local (ainda que tenham caráter e dimensão regional ou nacional), que não manipulam variáveis estruturais e, assim, estão longe de abalar a ordem capitalista, bem como a estrutura patrimonialista existente. Objetivando ampliar os argumentos a favor de uma possível mudança mais molecular, de longo prazo, poder-se-ia considerar que os autores entusiastas da GS estariam na árdua defesa de que as mudanças devem começar por baixo, de baixo para cima, do menor nível para o maior. Não desmerecendo as boas intenções dessas ações, acreditamos que o alcance que as mudanças estruturais requerem é indiscutivelmente mais amplo - ainda que, do ponto de vista estratégico, o local possa ser o ponto de partida.

Isso não significa desconsiderar a possibilidade de que possam existir experiências de democracia deliberativa, ou próximas a ela, nos vários recantos do País; mas, certamente, no nosso entender, infelizmente são casos isolados, periféricos, marginaise, às vezes, complementares ao sistema (ao nosso capitalismo patrimonialista), incapazes ou, ao menos, insuficientes para se constituírem em exemplo na direção da redefinição das práticas e da ordem existente. Por último, voltando à questão central deste artigo: o que é gestão social? Reafirmamos a tese de que, ainda que teoricamente o referido conceito (particularmente na versão teórica analisada) nos reporte à noção de democracia deliberativa, as experiências analisadas sugerem estarmos, em muito, distantes do seu exercício. É claro que as experiências analisadas, numericamente, não têm expressão estatística, mas se constituem em exemplo (lembrando que foram arroladas em um livro organizado justamente pelo scholar mais relevante da área de GS); são típicas do debate e práticas em questão. Um olhar mais apurado sugere que, do ponto de vista teórico, o que está sendo qualificado como GS são práticas, ações de gestão, do Estado, de entidades civis, nas distintas realidades e regiões do País, voltadas para determinados segmentos sociais, que objetivam a melhoria das condições 
de vida dos excluídos, como também a aceleração do crescimento (muitas dessas iniciativas devidamente circunscritas no projeto neodesenvolvimentista em curso); são projetos que envolvem, em graus diferenciados, a participação de segmentos organizados da população - e o significado político dessa participação no contexto do referido projeto de desenvolvimento, por si só, já é bastante polêmico. Entretanto, infelizmente, tais experiências estão longe, e muito longe, de realizar o ideário da gestão social, na forma conceitual proposta pelos seus ardorosos defensores.

\section{Referências bibliográficas}

Allebrandt, Sérgio L.; OliveirA, José R. de; DeCKert, Cristiele T. A gestão social no contexto do Programa Territórios da Cidadania: a experiência de alguns municípios do noroeste gaúcho. In: CANÇADO, Airton Cardoso; TENórıo, Fernando Guilherme; SILVA JR, Jeová Torres (Orgs.). Gestão social - aspectos teóricos e aplicações. Ijuí: Editora Unijuí, 2012.

Bethell, Leslie. Política no Brasil: de eleições sem democracia a democracia sem cidadania. In: BetHeLL, Leslie (Org.). Brasil: fardo do passado, promessa do futuro. Dez ensaios sobre política e sociedade brasileira. Rio de Janeiro: Civilização Brasileira, 2002. Tradução: Maria Beatriz Medina

Carvalho, José Murilo de. Entre a república e a democracia. Jornal Estado de São Paulo, 27 de dezembro 2009, in http://www.avozdocidadao.com.br/jose murilo carvalho entre republica e democracia.asp

FISCHER, T. M D. Poderes locais, desenvolvimento e gestão: uma introdução a uma agenda. In: FISCHER, T. M D. (Org.). Gestão do desenvolvimento e poderes locais: marcos teóricos e avaliação. Salvador: Casa da Qualidade, 2002. p. 12-32.

FischeR, T. M D.; Melo, V. P. Programa de desenvolvimento e gestão social: uma construção coletiva. In: FISCHER, T. M D.; RoESCH, S.; Melo, V. P. Gestão do desenvolvimento territorial e residência social: casos para ensino. Salvador: EDUFBA, CIAGS/UFBA, 2006. p.13-41.

FranÇA FILHo, Genauto C. de. Definindo gestão social. In: SılvA, Jeová Torres; MASH, Rogério Teixeira; CANÇAdo, Airton Cardoso; SCHOMMER, Paula Chies (Orgs.). Gestão Social: práticas em debate, teorias em construção. Fortaleza: Imprensa Universitária, 2008.

IIZUKA, Edson Sadao; JUNQUEIRA, Luciano A. Prates. Produção acadêmica em gestão social: visita aos anais dos ENAPEGS de 2007 a 2012. Salvador, Anais do XII Colóquio de Poder Local. CIAGS. Escola de Administração - UFBA, 2012.

LAMOUNIER, Bolivar. Bases do autoritarismo revisitado: diálogo com Simon Schwartzman sobre o futuro da democracia brasileira. In: SCHWARTZMAN, Luisa F.; SCHWARTZMAN, Isabel F.; SCHWARTZMAN, Felipe F.; LENT, Michel (Orgs.). O sociólogo e as políticas públicas: ensaios em homenagem a Simon Schwartzman. Rio de Janeiro: Editora FGV, 2009. p. 53-66. 
Martins, José de Souza. A política do Brasil. Lúmpen e Místico. São Paulo: Editora Contexto, 2011.

Melo, Rúrion. Marx e Habermas - teoria crítica e os sentidos da emancipação. São Paulo: Editora Saraiva, 2013.

Nogue ra, Marco Aurélio. As possibilidades da política: idéias para a reforma democrática do Estado. São Paulo: Paz e Terra, 1998.

O’DonNeLL, Guillermo. Transições, continuidades e alguns paradoxos. In: REIS, Fábio Wanderley; O’DonNELL, Guillermo (Orgs.). A democracia no Brasil: dilemas e perspectivas. São Paulo: Vértice, 1988.

Democracia delegativa? Novos Estudos, São Paulo, no 31, p. 25-40, out. 1991.

PINHo, José Antonio G. de; SANTOS, Maria Elisabete. Aporias em torno do conceito de gestão social: dilemas teóricos e políticos. Rio de Janeiro: EnANPAD, 2013.

SChOMmer, Paula; FrançA FILHo, Genauto. Gestão social e aprendizagem em comunidades de prática: interações conceituais e possíveis decorrências em processos de formação. In: SILVA, Jeová Torres; MASH, Rogério Teixeira; CANÇADO, Airton Cardoso; ScHommer, Paula Chies(Orgs.). Gestão social: práticas em debate, teorias em construção. Fortaleza: Imprensa Universitária, 2008.

SCHWARTZMAN, Simon. Bases do autoritarismo brasileiro. 4. Ed. Rio de Janeiro: Publit Soluções Editoriais, 2007.

SiLva JR, Jeová Torres; GrangeIRo, Rebeca R. Gestão social, finanças solidárias e desenvolvimento territorial: os impactos dos 10 anos do Banco Palmas. In: CANÇADo, Airton Cardoso; TENórıo, Fernando Guilherme; SILVA JR., Jeová Torres(Orgs.). Gestão social - aspectos teóricos e aplicações. Ijuí: Editora Unijuí, 2012.

SORJ, Bernardo. A nova sociedade brasileira. Rio de Janeiro: Zahar, 2001.

TENÓRIO, Fernando Guilherme. (Re)visitando o conceito de gestão social. In: SILVA, Jeová Torres; MASH, Rogério Teixeira; CANÇADO, Airton Cardoso; SCHOMmER, Paula Chies (Orgs.). Gestão social: práticas em debate, teorias em construção. Fortaleza: Imprensa Universitária, 2008.

Gestão social: uma réplica. In: RIGO, Ariádne S.; SILVA JR, Jeová Torres; SCHOMMER, Paula C.; CANÇADO, Airton C. (Orgs.). Gestão social e políticas públicas de desenvolvimento: ações, articulações e agenda. Recife: UNIVASF, 2010.

TENóRıO, Fernando Guilherme et al. Critérios para a avaliação de processos decisórios participativos deliberativos na implementação de políticas públicas. In: Encontro de Administração Pública e Governança, 2008, Salvador-Ba. Resumo dos trabalhos .... Rio de Janeiro: ANPAD, 2008. v. 1, p.1-16.

VILLELA, Lamounier E.; COSTA, Eduardo G. da. Avaliação de processos decisórios participativos no polo comercial Saara situado na cidade do Rio de Janeiro: uma fórmula de sucesso com problema em seu princípio ativo, a participação. In: CANÇADO, Airton Cardoso; TenóRIO, Fernando Guilherme; Silva JR., Jeová Torres (Orgs.). Gestão social - aspectos teóricos e aplicações. ljuí: Editora Unijuí, 2012. 
ZANI, Felipe B.; KRONENBERger, Thias S.; DiAS, Anderson F. Gestão social aplicada às políticas públicas de desenvolvimento territorial rural no Brasil: o caso do território da cidadania norte do Rio de Janeiro. In: CANÇADo, Airton Cardoso; TEnório, Fernando Guilherme; SILVA JR., Jeová Torres (Orgs.). Gestão social - aspectos teóricos e aplicações. Ijuí: Editora Unijuí, 2012.

José Antonio Gomes de Pinho

Professor Associado IV da Escola de Administração da UFBA. PhD em Regional Planning pela Universidade de Londres (LSE). Mestre em Engenharia da Produção (Planejamento Urbano) pela COPPE-UFRJ. Contato: jagp@ufba.br.

Maria Elisabete Pereira dos Santos

Professora Adjunta III da Escola de Administração da UFBA. Doutora em Ciências Sociais pela Unicamp. Mestre em Sociologia pela UFBA. Contato: betesantos28@gmail.com. 